\title{
Ethics of the social determinants of health
}

\author{
Jennifer Prah Ruger, PhD \\ Department of Epidemiology and Public Health, School of Medicine, Yale University, New Haven, \\ CT 06520, USA
}

Research over several decades has identified social inequalities in health, both between and within countries. ${ }^{1-3}$ This research has prompted some countries to pursue strategies to reduce socioeconomic inequalities in health, ${ }^{4-7}$ although these initiatives have not been without controversy. ${ }^{8-11}$ Such efforts have fuelled the debate over the relative contributions of health determinants and how to weight and direct public policies that affect health. ${ }^{12-17}$ The debate centres on the tension between the need to account for the impact of health determinants outside the health-care system (social determinants of health) and the need to balance health as an objective with other valuable social ends (in other policy domains).

Alongside this practical debate exists a parallel debate at the philosophical level; ${ }^{18-23}$ one that will in many ways inform the policy choices that societies make to improve the health of their populations. The implications of theories of justice (eg, fair and equitable treatment of people) for social determinants of health has thus become an important topic of philosophical inquiry, although little work has been done in this area. ${ }^{19-21}$ Although a survey of the main issues relating to the fairness of social inequalities in health has been provided elsewhere, ${ }^{19,21-23}$ this essay focuses more specifically on the application of John Rawls' theory of justice to the social determinants of health and then proposes an alternative philosophical framework, rooted in Amartya Sen's capability approach and Aristotle's political theory, for thinking about such inequalities.

\section{Justice as fairness}

An important starting point for a philosophical discussion of the social determinants of health is the application of John Rawls' theory of justice to such determinants. ${ }^{18,21}$ In $A$ theory of justice, Rawls ${ }^{24}$ argued that justice requires the fair distribution of primary goods and that rational people behind a "veil of ignorance" about their personal circumstances would choose principles of justice that maximise the minimum level of primary goods. Primary goods are allocated to individuals on the basis of "fair equality of opportunity", due to the disadvantages that these individuals have accrued through the "natural lottery" and the "social lottery" of life. ${ }^{24}$

In applying Rawls' theory to the social determinants of health, Norman Daniels and colleagues ${ }^{18,25}$ argue that justice requires flattening "socioeconomic inequalities in a robust way, assuring far more than a decent minimum". From this point of view, "a society 
complying with these principles of justice would probably flatten the socioeconomic gradient even more than we see in most egalitarian welfare states of northern Europe". ${ }^{18}$ The implications, they argue, are that "we should view health inequalities that derive from social determinants as unjust unless the determinants are distributed in conformity with these robust principles." 18 From a policy perspective, therefore, governments should pursue social strategies (to reduce health inequalities) by implementing policies "aimed at equalizing individual life opportunities, such as investment in basic education, affordable housing, income security and other forms of antipoverty policy". ${ }^{25}$ Daniels and colleagues give at least five examples of social policies that might improve health by reducing socioeconomic disparities: investment in early childhood development, nutrition programmes, improvements in the quality of the work environment, reductions in income inequality, and greater political fairness. ${ }^{25}$

Although there is much to applaud in a Rawlsian analysis of the social determinants of health, this approach has not been spared criticism. Some critics are concerned that these policy prescriptions are too far-reaching without sufficient evidence of their effect on population health. ${ }^{26}$ Francis $\mathrm{Kamm}^{27}$ notes, for example, that policy proposals related to social inequality and health must compare the health gained by economic growth associated with social inequality with the health that would be gained from complete social equality. These types of comparisons are necessary to fully understand the net effects of policy measures. ${ }^{27}$ Barbara Starfield ${ }^{16}$ adds that although "income redistribution may go a long way to improve health", there also has to be "simultaneous attention to changing other social and health policies.... There is no simple solution to reducing systematic health inequalities." 16 Ezekiel Emanuel ${ }^{28}$ and Ted Marmor ${ }^{15}$ have made similar points, and have added concerns about the political and policy problems associated with the strategy of eliminating all socioeconomic inequalities.

Sudhir Anand and Fabienne Peter ${ }^{20}$ offer a critique that underscores the importance of taking into account health differentials between and within multiple groups (eg, between African-American and white men with the same income levels)—not just average health across socioeconomic groups. They also expressed concern that attention to health inequalities is indirect (eg, a "side-effect") in the analysis of Daniels and others, and highlight the problem in using Rawls' original theory to come up with the premise that "inequalities in health are unjust if, and only if, they are the result of unjust social arrangements". ${ }^{20}$ Ezekiel Emanuel and Emmanuela Gakidou and colleagues independently reiterated this critique, expressing concern with the idea of justifying improvements in social justice based primarily on their impact on health inequalities. ${ }^{28,29}$ They also underscore how complex the relation is between socioeconomic status and health inequalities and the need for further study. ${ }^{29}$

Anand and Peter go on to argue that there is a tension in using different aspects of Rawlsian justice because such views might conflict in their policy recommendations and might therefore be redundant. In a sense, Daniels and colleagues are still treating socioeconomic and health inequalities as independent spheres of justice, ${ }^{30}$ but they provide little guidance when accounts of social and economic justice conflict with accounts of justice with respect to health. ${ }^{30}$ For example, "economic inequalities permitted by Rawls's Difference Principle 
may cause health inequalities that are condemned by the account of health equity". ${ }^{30}$ Justice and health needs a philosophical framework for assessing tradeoffs between health inequity and other inequities. It is insufficient to assume that "health is the by-product of justice". ${ }^{31}$

At a more fundamental level, Amartya Sen, ${ }^{32-34}$ and more recently Michael Marmot, ${ }^{35}$ have expressed concerns with the Rawlsian focus on means rather than ends because it does not take account of human diversity. The Rawlsian approach is problematic, they argue, because resources and means cannot be good in their own right-they have no intrinsic value (they cannot be the object of social activity), they are good only insofar as they promote human functioning. ${ }^{32-34}$ As Sen notes, "if the object is to concentrate on the individual's real opportunity to pursue her objectives (as Rawls explicitly recommends), then account would have to be taken not only of the primary goods the persons respectively hold, but also of the relevant personal characteristics that govern the conversion of primary goods into the person's ability to promote her ends. For example, a person who is disabled may have a larger basket of primary goods and yet have less chance to lead a normal life (or to pursue her objectives) than an able-bodied person with a smaller basket of primary goods." 34 Ensuring possession of primary goods, therefore, might not address inequalities in health; that reduction of socioeconomic inequality will necessarily lead to reductions in health inequalities should not be assumed. ${ }^{35,36}$ It therefore cannot be said that it is necessarily the case that "health is the by-product of justice", since this "oversimplifies the demands of health equity vis-à-vis the extensive requirements of social justice". ${ }^{36}$ This critique throws light on the distinction between a "resource-orientation" (Rawlsian) and a resultsorientation" (capability) in public policy. Thus, although a focus on fair distribution of primary goods and equal opportunity is a useful way of elevating the importance of the social determinants of health, this view has limitations, especially in acknowledging the intrinsic value of health and other capabilities in analysing the relative effectiveness of resources on health and health inequalities, and in understanding public policy more broadly. 37,38

\section{A capability perspective}

By contrast with Rawls' theory and other well-known philosophies, Amartya Sen developed the capability approach. ${ }^{32-34}$ This philosophical framework, with roots in Aristotle's political theory, ${ }^{39-43}$ applies to the social determinants of health, ${ }^{37,38}$ but it is more "people centred" and "agency-oriented" in its philosophical basis and more nuanced in its practical application. This view sees the expansion of human capabilities-the real freedoms that people have-as the ultimate end of public policy. As such, it values health intrinsically and more directly than non-intrinsic or solely instrumental social goods such as income or health care. ${ }^{37,38}$ In this context, different kinds of capabilities (eg, the capability to avoid preventable morbidity and premature mortality, or to be literate and numerate) are regarded both as ends in themselves and instrumentally important for the achievement of other (also intrinsically valued) ends (eg, economic facilities [such as the capability for participation in trade and production] and political freedoms). For example, the degree to which individuals have the capability to participate actively in their work, social, and political life, to be welleducated or to be secure in their economic facilities are ends in themselves, but they may also be related to individuals' capability for health functioning since the lack of those 
capabilities could be harmful to health—as Michael Marmot and colleagues' work suggests. ${ }^{1-3,44,45}$ Thus, such social determinants of health have both constitutive and instrumental value, and they serve not only to contribute to the "general capability of a person to live more freely, but they also serve to complement one another", as stated by Sen. ${ }^{34}$

Indeed, often such freedoms as economic facilities, social opportunities (eg, capability to avoid premature mortality and to be well educated), political freedoms (eg, capability for self-determination), and protective security (eg, capability to avoid economic vulnerability) will supplement one another and "strengthen their joint importance". ${ }^{34}$ For example, better education for women reduces child mortality directly through a woman's expanded ability and desire to obtain, understand, and act on health-related information, but also indirectly by increasing her respect and empowerment in intrafamilial and extrafamilial decision-making. Lower child mortality rates, in turn, help reduce birth rates, reinforcing the influence of better education, on fertility. As Sen notes, "different kinds of freedom inter-relate with one another, and freedom of one type may greatly help in advancing freedom of other types". 34 Conversely, the coupling of disadvantages can exacerbate an individual's overall freedom, for example, a disabled person might have difficulty both in earning a decent income and in converting more income into capabilities. ${ }^{34}$ Income inequality assessment alone, therefore, cannot tell us how well such a person is living.

The capability perspective is also an agency-oriented view. It emphasises the importance of human agency-ie, people's ability to live a life they value. It underscores that agency is essential for both individual and collective action and is critical for changing policy, norms, and social commitments. Reducing social inequalities in health therefore requires more than "flattening the socioeconomic gradient", it requires improvement of the conditions under which individuals are free to choose healthier life strategies and conditions for themselves and for future generations. ${ }^{37,46} \mathrm{~A}$ capability perspective emphasises the empowerment of individuals to be active agents of change in their own terms-both at the individual and collective level. ${ }^{37,46}$ Agency is important for public policy because it supports individuals' participation in economic, social, and political actions and enables individuals to make decisions as active agents of change. This view contrasts with the perspective that individuals are passive recipients of medical care or even income redistribution decisions or other public-policy programmes. An agency-centred view promotes individuals' ability to understand and "shape their own destiny and help each other". ${ }^{34}$

\section{A broad and multifaceted approach}

A capability approach to the social determinants of health thus recognises the importance of addressing health needs on multiple fronts, in multiple domains of policy that affect all determinants of health (not just socioeconomic inequalities). It emphasises the integration of public policies into a comprehensive set of health improvement strategies delivered through a plurality of institutions. Information about the factors and processes that can improve health (and reduce health inequalities) should form the basis of policies designed to avert health problems. According to Sen, such policies may address a number of different influences, such as "individually inherited proneness to disease, individual characteristics of 
disability, epidemiological hazards of particular regions, the influence of climate variations" ${ }^{36}$ Public policies should focus on making "simultaneous progress on different fronts, including different institutions, which reinforce each other". ${ }^{34}$ This "integrated and multifaceted" 34 approach supports the idea that society is obligated to reduce inequalities in the capability for functioning (including health functioning), and it recognises the "respective roles and complementarities" of different kinds of capabilities. ${ }^{34}$ However, this approach extends this reach with caution; recognising that considerable work is to be done to better understand the relative impacts of various policy domains (including politics) ${ }^{8}$ and their inter-relationships before embarking on major social changes. ${ }^{36}$ This approach is also cautious about extending the traditional boundaries of health policy to include all policy domains that affect health and about assuming that social and economic policy reforms will be associated with health improvement in a linear way (eg, the relation between income and health could be variable and depend on a number of factors such as age, gender, job status, location, and environment). ${ }^{36}$ As Michael Marmot ${ }^{47}$ notes, the idea of abolishing hierarchies altogether, and making everyone exactly the same, does not seem promising for public policy. So before abolishing hierarchies, we need to understand the precise factors that influence health, including the underlying political structure. We must then determine how to weight different social objectives, once we have this information. The capability perspective thus rejects a narrow and compartmentalised view of inequality (eg, focus on income distribution $)^{8}$ and the search for a "single all-purpose remedy" 34 for reducing health inequalities. Several distinctions are relevant to this viewpoint.

First, such an approach necessitates improving the assessment of other (non-health-sector) policy domains, such as employment policy, by using health indicators as well as traditional indicators (eg, employment rates). For example, in terms of economic policy, a capability approach would be concerned not only with whether a person's annual income falls below society's average, but with the extent to which that person's income level affects his or her health. This suggests that analysis of mortality and morbidity data can be used as an additional indicator in evaluating economic and social arrangements, to take into account the effect of these policies on health. In developing countries, in particular, economic arrangements have been found to be critical for preventing death and avoiding disease and disability. For example, one study of famine and under-nourishment found that starvation results when a large proportion of the population loses the means of obtaining food and that this loss results from three economic factors: unemployment; a fall in the purchasing power of wages; and a shift in the exchange rate between goods and services sold and food bought. ${ }^{48}$ Policy recommendations to prevent famines and reduce starvation would then, according to these results, incorporate improvements in these three economic factors (nonhealth sector domains) and information about the effects of these factors should necessarily "form the basis of policies designed to avoid famine and relieve hunger". ${ }^{48}$ Thus, the more conventional ways of measuring the effectiveness of economic and social policies can be enhanced by indicators of a population's health that illuminate important aspects of social inequality, help understand the relation between these factors and health, and identify policies to address these disparities. Adding such measures to the existing array of policy indicators might improve assessment of all policies that affect health, while maintaining the strengths of other public policy domains. 
Second, information about the factors and processes that can improve health should form the basis of policies designed to avert health problems. However, the traditional boundaries of health policy should not be extended to include all policy domains that affect health, such as employment policy for example. Employment policy may be a useful way of thinking about health policy, but is not a substitute. For instance, employment indicators are not necessarily valid for assessing health policies because a person who is unemployed but wealthy does not necessarily incur the same morbidity and mortality risks as an unemployed person with no financial support. Moreover, an employed person might have a high degree of stress or lack of control, which could precipitate illness. Thus, employment status alone should not be identified with health policy in a linear way; the crucial information is the extent to which it affects a person's health.

Third, although health policy and other policies must remain separate, it is important not to assume that they are independent, especially in developing countries. Thus, while health policy and other public policies affecting health are related, it is important to keep the concepts of health policy and other policies distinct, without assuming them to be independent of each other. So, before giving substantially greater weight to broader socioeconomic policies than to health policies, we need to understand the precise mechanisms through which various factors influence health. We must then determine how to weight different social objectives, once we have this information. In light of existing information on social determinants of health, it would be unwise to prescribe sweeping policies, such as completely flattening of socioeconomic inequalities, in an effort to improve health. Such prescriptions blur, rather than clarify, the means and ends of health policy, hindering evaluations of the impact of public policies on health.

Fourth, such an approach to public policy would also likely entail what could be called horizontal and vertical integration, respectively. The horizontal dimension integrates policies across disease-specific programmes to create a comprehensive package of complementary interventions to improve health. In North America, western Europe, Australia, Brazil, Senegal, Thailand, and Uganda, for example, the spread of HIV/AIDS has been slowed through multiple prevention strategies, including: health education; behaviour modification; social, economic, and political environments that allow individuals to protect themselves against infection; condom promotion; HIV counselling and testing; blood safety; reduction in mother-to-child transmission; needle-exchange programmes; and treatments for sexually transmitted infections. ${ }^{46,49}$ Such an integrated set of strategies has also been more effective than narrower approaches for controlling tobacco use in a number of countries. ${ }^{50}$ Successful efforts have included simultaneous bans on advertising and promotion and on sales to children, mandatory health warnings, smoke-free environments, higher taxes on tobacco products, investment in health education, and smoking prevention and cessation programmes. $^{50}$

The vertical dimension integrates domains of public policy that build upon each other. For example, better education, especially for women, makes individuals more likely to protect themselves from contracting sexually transmissible diseases including HIV/ AIDS ${ }^{46,49}$ And improved economic, cultural, and social conditions for women - through, for example, real employment, political, and civil opportunities that empower them within the family and in 
their relationships with men-enhances the effectiveness of HIV/AIDS prevention and treatment programmes because such freedoms enable women to choose safer life strategies for themselves and their children. ${ }^{46}$ Improving a woman's agency and education, thus, can improve the health of herself and her family, which in turn can improve overall health in a developing country. ${ }^{46}$

Fifth, the capability perspective also recognises the importance of a many-sided approach that addresses the functions of plural institutions, including non-governmental actors and market forces to achieve public policy objectives. This contrasts with a predominant focus on government action and intervention (eg, on the governmental redistribution system), important as that is. For example, government agencies can widely distribute health information, while market-based approaches can expand employment opportunities for women and non-governmental organisations can provide aid and technical assistance in the health sector. The movement in global health toward better public-private partnerships reflects this view, but such efforts should be more closely linked with specific health improvement efforts and broader development activities. ${ }^{51}$

\section{Conclusion}

It is important to reflect on the richness of the Rawlsian approach to social justice generally and to the social determinants of health more specifically. Such efforts have advanced our thinking about health equity and its determinants. Despite its many strengths, however, the Rawlsian approach has limitations; an alternative approach to health and its determinants (within and outside the health sector) is found in Sen's capability approach. This approach takes human capabilities and freedoms as the real ends of public policy and calls for an integrated and multifaceted approach to health improvement that involves multiple institutions making simultaneous progress on various fronts. Although this more comprehensive approach may seem less deterministic, its more nuanced application calls for institutional arrangements to support greater freedoms for all persons so that people can "help themselves", "support each other", and "influence the world."34

\section{Acknowledgments}

I thank Amartya Sen, Sudhir Anand, Michael Marmot, and participants in the workshop on Rights, Dignity, and Inequality at Trinity College, Cambridge, UK, for helpful comments. I also thank the Washington University School of Medicine and Centre for Health Policy for support. J P Ruger is supported in part by a Career Development Award (grant 1K01DA016358-01) from the US National Institutes of Health.

\section{References}

1. Marmot MG. Inequalities in health. N Engl J Med. 2001; 345:134-136. [PubMed: 11450663]

2. Amick, BC.; Levine, S.; Tarlov, AR.; Chapman, D., editors. Society and health. New York: Oxford University Press; 1995.

3. Marmot MG. Improvement of social environment to improve health. Lancet. 1998; 351:57-60. [PubMed: 9433438]

4. Acheson, D. Independent inquiry into inequalities in health report. London: Stationery Office; 1998.

5. Reducing health inequalities: an action report. London: Stationery Office; 1999.

6. Mackenbach JP, Stronks K. A strategy for tackling health inequalities in the Netherlands. BMJ. 2002; 325:1029-1032. [PubMed: 12411368] 
7. Black D, Morris JN, Smith C, Townsend P. Better benefits for health: plan to implement the central recommendation of the Acheson report. BMJ. 1999; 318:724-727. [PubMed: 10074023]

8. Horton R. What the UK government is (not) doing about health inequalities. Lancet. 2002; 360:186. [PubMed: 12133651]

9. Smith GD, Morris JN, Shaw M. The independent inquiry into inequalities in health is welcome, but its recommendations are too cautious and vague. BMJ. 1998; 317:1465-1466. [PubMed: 9831567]

10. Evans, PG.; Barer, ML.; Marmor, TR., editors. Why are some people healthy and others not?. New York: Aldine de Gruyer; 1994.

11. Macintyre S. Prevention and the reduction of health inequalities. BMJ. 2000; 320:1399-1400. [PubMed: 10818038]

12. Leon DA, Walt G, Gilson L. International perspectives on health inequalities and policy. BMJ. 2001; 322:591-594. [PubMed: 11238156]

13. Deaton A. Policy implications of the gradient of health and wealth: an economist asks, would redistributing income improve population health? Health Affairs. 2002; 21:13-30. [PubMed: 11900153]

14. Martikainen $P$, Valkonen T. Inequalities in health: policies to reduce income inequalities are unlikely to eradicate inequalities in mortality. BMJ. 1999; 319:319. [PubMed: 10426760]

15. Marmor T. Policy options. Boston Review. 2000; 25 Available from: http://bostonreview.net/ BR25.1/marmor.html.

16. Starfied B. First contact. Boston Review. 2000; 25 Available from: http://bostonreview.net/ BR25.1/starfield.html.

17. Woolhandler S, Himmelstein D. Lost in translation. Boston Review. 2000; 25 Available from: http://bostonreview.net/BR25.1/woolhandler.html.

18. Daniels, N. Justice, health, and health care. In: Rhodes, R.; Battin, MP.; Silvers, A., editors. Medicine and social justice: essays on the distribution of health care. New York: Oxford University Press; 2002. p. 6-23.

19. Evans, T.; Whitehead, M.; Diderichsen, F.; Bhuiya, A.; Wirth, M., editors. Challenging inequities in health: from ethics to action. London: Oxford University Press; 2001.

20. Anand S, Peter F. Equal opportunity. Boston Review. 2000; 25 Available from: http:// bostonreview.net/BR25.1/anand.html.

21. Peter, F.; Evans, T. Ethical dimensions of health equity. In: Evans, T.; Whitehead, M.; Diderichsen, F.; Bhuiya, A.; Wirth, M., editors. Challenging inequities in health: from ethics to action. London: Oxford University Press; 2001. p. 24-33.

22. Macinko JA, Starfield B. Annotated bibliography on equity in health, 1980-2001. Int J Equity Health. 2002; 1:1-20. [PubMed: 12234390]

23. Braveman P, Gruskin S. Defining equity in health. J Epidemiol Community Health. 2003; 57:254258. [PubMed: 12646539]

24. Rawls, J. A theory of justice. Cambridge, MA: Harvard University Press; 1971.

25. Daniels N, Kennedy B, Kawachi I. Justice is good for our health: how greater economic equality would promote public health. Boston Review. 2000; 25 Available from: http://bostonreview.net/ BR25.1/daniels.html.

26. Angell M. Pockets of poverty. Boston Review. 2000; 25 Available from: http://bostonreview.net/ BR25.1/angell.html.

27. Kamm FM. Health and equality of opportunity. Am J Bioeth. 2001; 1:17-19. [PubMed: 11951871]

28. Emanuel EJ. Political problems. Boston Review. 2000; 25 Available from: http://bostonreview.net/ BR25.1/emanuel.html.

29. Gakidou E, Frenk J, Murray C. A health agenda. Boston Review. 2000; 25 Available from: http:// bostonreview.net/BR25.1/frenk.html.

30. Brock D. Broadening the bioethics agenda. Kennedy Inst Ethics J. 2000; 10:21-38. [PubMed: 11658153]

31. Daniels, N.; Kennedy, B.; Kawachi, I. Is inequality bad for our health?. Boston, MA: Beacon Press; 2000.

32. Sen, AK. Commodities and capabilities. Amsterdam: North-Holland; 1985. 
33. Sen, AK. Inequality reexamined. Cambridge, MA: Harvard University Press; 1992.

34. Sen, AK. Development as freedom. New York: Knopf; 1999.

35. Marmot MG. Do inequalities matter? Boston Review. 2000; 25 Available from: http:// bostonreview.net/BR25.1/marmot.html.

36. Sen, AK. Foreword. In: Cohen, J.; Rogers, J., editors. Is inequality bad for our health?. Boston, MA: Beacon Press; 2000.

37. Ruger, JP. PhD thesis. Cambridge, MA: Harvard University; 1998. Aristotelian justice and health policy: capability and incompletely theorized agreements.

38. Ruger JP. Health and development. Lancet. 2003; 362:678. [PubMed: 12957088]

39. Welldon, JEC., translator. Aristotle. The Nicomachean ethics. Amherst, NY: Prometheus Books; 1987.

40. Nussbaum, MC. Nature, function, and capability: Aristotle on political distribution. In: von Gunther Patzig, H., editor. Aristoteles Politik. Gottingen: Vandenhoeck and Ruprecht; 1990.

41. Nussbaum, MC. The good as discipline, the good as freedom. In: Crocker, DA.; Linden, T., editors. The ethics of consumption and global stewardship. Lanham, MD: Rowman and Littlefield; 1998. p. 312-341.

42. Nussbaum MC. Human functioning and social justice: in defense of Aristotelian essentialism. Polit Theory. 1992; 20:202-246.

43. Lord, C., translator. Aristotle. The politics. Chicago, IL: University of Chicago Press; 1984.

44. Marmot MG, Shipley MJ, Rose G. Inequalities in death: specific explanation of a general pattern. Lancet. 1984; 1:1003-1006. [PubMed: 6143919]

45. Marmot MG, Smith GD, Stansfeld S, et al. Health inequalities among British civil servants: the Whitehall II study. Lancet. 1991; 337:1387-1393. [PubMed: 1674771]

46. Ruger JP. Combating HIV/AIDS in developing countries. BMJ. 2004; 329:121-22. [PubMed: 15258043]

47. Kreisler, H. Sir Michael Marmot Interview: conversations with History. UC Berkeley: Institute of International Studies; 2002 Mar 18. Redefining public health: epidemiology and social stratification. Available from: http://globetrotter.berkeley.edu/people2/Marmot/marmot-con1.html [accessed Feb 6, 2004]

48. Sen AK. The economics of life and death. Sci Am. 1993; 268:40-47. [PubMed: 8480166]

49. United Nations. Preventing HIV/AIDS. Available from: http://www.unaids.org/en/other/ functionalities/ViewDocument.asp?href=http $\% 3 \mathrm{a} \% 2 \mathrm{f} \% 2 \mathrm{fgva}-$ doc-owl $\% 2 \mathrm{fWEBcontent}$ $\% 2 \mathrm{fDocuments} \% 2 \mathrm{fpub} \% 2 \mathrm{fPublications} \% 2 \mathrm{fFact}-\mathrm{Sheets} 02 \% 2 \mathrm{fFS} \_$prevention_en $\% 26 \% 2346 \% 3$ bpdf.

50. World Bank. Curbing the epidemic: governments and the economics of tobacco control. Washington, DC: World Bank; 1999.

51. Ruger JP. Changing role of the World Bank in global health. Am J Public Health. (in press). 


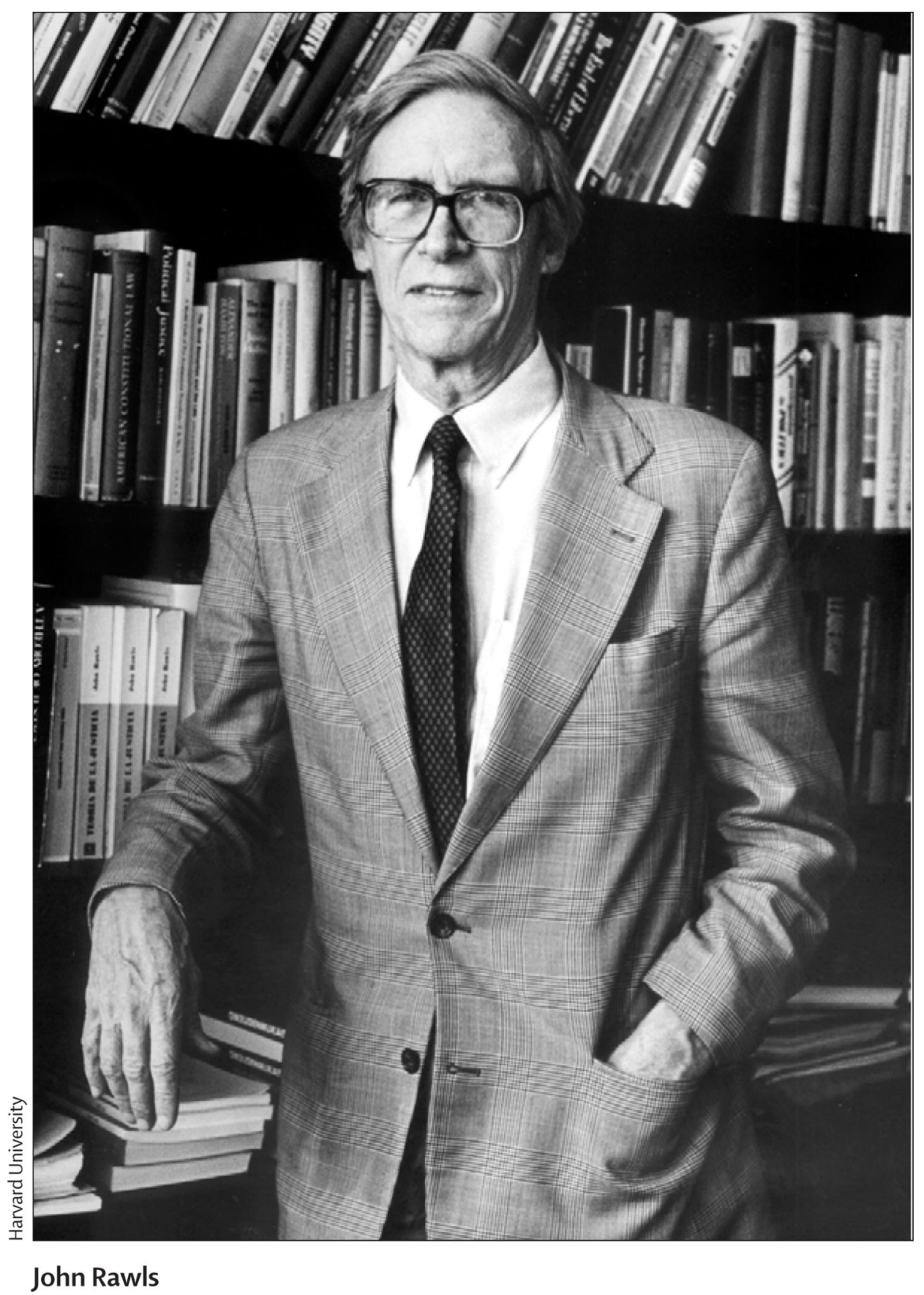

Figure 1.

John Rawls 